\title{
Nghiên cứu về nghệ thuật Việt Nam đạt 7000 lượt đọc trên tạp chí Arts
}

\author{
Hồ Mạnh Toàn
}

Centre for Interdisciplinary Social Research, Phenikaa University

\author{
ISR Phenikaa, 3/1/2019 4:51 PM \\ URL: http://isr.phenikaa-uni.edu.vn/chitiet/thong-bao 2019222758 66/nghien- \\ cuu-ve-nghe-thuat-dat-7000-luot-doc
}

Trung tâm ISR (01-03-2019) - Tháng 10 năm 2018, trung tâm ISR đại học Phenikaa đã công bố nghiên cứu đầu tiên về nghệ thuật trên tạp chí Arts [ESCI], khám phá thị trường tranh Việt Nam từ góc nhìn về tranh giả. Sau hơn 5 tháng, nghiên cứu vẫn giứ nguyên được sức hút của mình khi chạm mốc 7000 lượt đọc, 1550 lượt downloads theo thống kê trên trang chủ của tạp chí. Nghiên cứu hiện xếp thứ 2 trong danh sách các nghiên cứu được xem nhiều nhất của tạp chí Arts. 

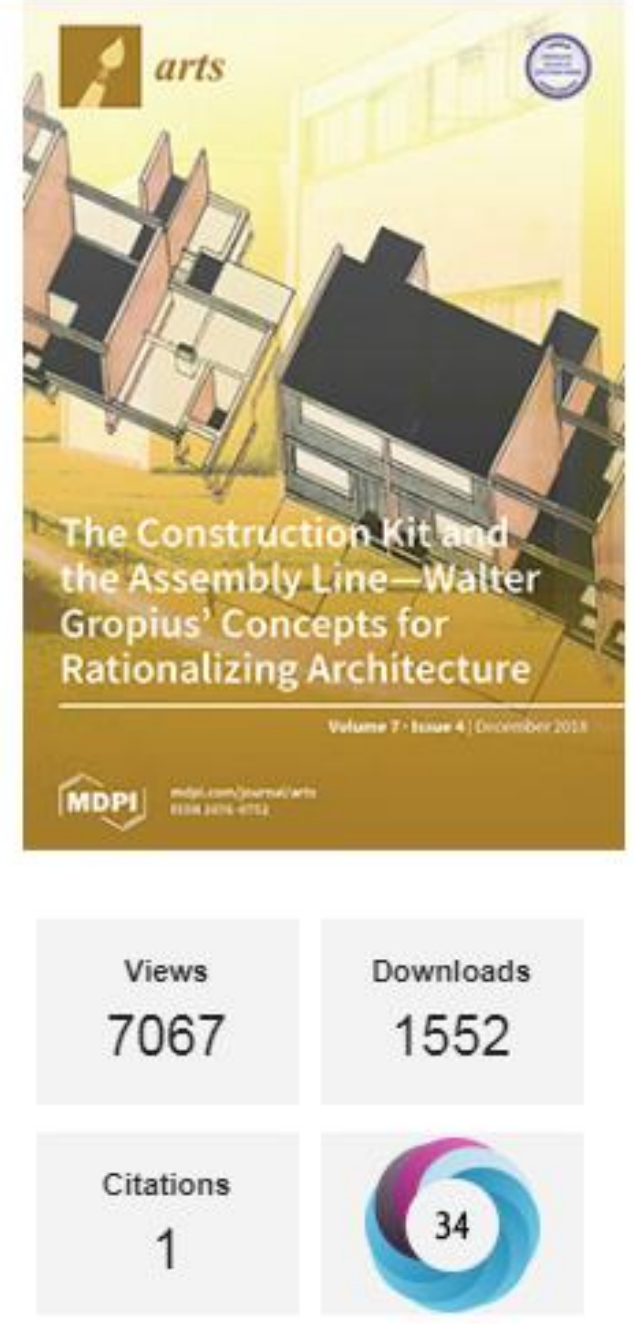

Hình 1: Thống kê lượt đọc, downloads, trích dẫn và điểm Almetric của nghiên cứu (Tính đến ngày 01-03-2019) 


\begin{tabular}{|c|c|}
\hline Most Cited & Most Viewed \\
\hline \multicolumn{2}{|c|}{ Articles published: All time | Last 6 months | Last 12 months | Last 24 months | Last 36 months } \\
\hline Views & Article \\
\hline 9022 & $\begin{array}{l}\text { Essay: Can Computers Create Art? } \\
\text { by Aaron Hertzmann }\end{array}$ \\
\hline 7064 & $\begin{array}{l}\text { Article: "Paintings Can Be Forged, But Not Feeling": Vietnamese Art-Market, Fraud, and Value } \\
\text { by Quan-Hoang Vuong, Manh-Tung Ho, Hong-Kong T. Nguyen, Thu-Trang Vuong, Kien Tran and } \\
\text { Manh Toan Ho }\end{array}$ \\
\hline 6063 & $\begin{array}{l}\text { Essay: Swing Low, Sweet Chariot: Kinetic Sculpture and the Crisis of Western Technocentrism } \\
\text { by G. W. Smith }\end{array}$ \\
\hline
\end{tabular}

Hình 2: Top 3 nghiên cứu được đọc nhiều nhất của tạp chí Arts

\section{References:}

Vuong, Q. H., Ho, M. T., Vuong, T. T., Tran, K., \& Ho, M. (2018). "Paintings can be forged, but not feeling": Vietnamese art-Market, fraud, and value. Arts, 7(4), 62; DOI: $10.3390 / \operatorname{arts} 7040062$. 